\title{
Congenital idiopathic nystagmus in identical twins
}

\author{
RICHARD V. ABADI, ${ }^{1}$ CHRISTINE M. DICKINSON,${ }^{1}$ MARK S. LOMAS, \\ AND ROGER ACKERLEY ${ }^{2}$ \\ From the ${ }^{1}$ Department of Ophthalmic Optics, UMIST, Manchester, and the ${ }^{2}$ Department of \\ Ophthalmic Optics, Glasgow College of Technology, Glasgow
}

SUMMARY Using an infrared recording system we examined the nystagmus waveforms of a pair of monozygotic twin girls and found them to be dissimilar. It is proposed that in view of the common mode of inheritance the differences are a result of environmental influences.

The past decade has seen a transformation in the approach to the study of congenital nystagmus $(\mathrm{CN})$. Though some research has been carried out on the sensory effects of the nystagmus ${ }^{1-3}$ most has been directed towards understanding the motor characteristics of the disorder..$^{4-13}$ Notably, Dell'Osso and his colleagues have carefully established that 12 distinct waveforms may be distinguished. ${ }^{813}$ These oscillations are not related to any one aetiology. ${ }^{913}$ Nor do they appear to have a common genetic heritage, since 3 members of the same family have been shown to have different nystagmus waveforms. ${ }^{7}$

In the present study the eye movements of a pair of identical twins with $\mathrm{CN}$ will be described. The twin girls, being genetically identical, should presumably

Correspondence to Dr R. V. Abadi, Department of Ophthalmic Optics, UMIST, PO Box 88, Manchester M60 1QD. provide a pointer to the extent of environmental influences, since any difference arising between the monozygotic twins must be due to nongenetic factors.

\section{Case report}

The twins were full-term babies born on 12 August 1967 , and the nystagmus was noticed soon after birth. There is no known family history of congenital nystagmus. The twins (Fig. 1) were 13 years old at the time of this study.

An analysis of finger print total ridge counts and serum and red cell polymorphic markers indicated that the girls are monozygotic twins. The twins were concordant for the following markers: ABO, MNS, rhesus, Lutheran, Kell, Lewis, Duffy, Kidd, secretor, haptoglobin, transferrin, GM, Inv, esterase 2,
Fig. 1 Identical twin girls with a bilateral, conjugate, horizontal, idiopathic congenital nystagmus. Twin $A$ is pictured on the left. Before this photograph was taken both girls had their left pupils dilated so that their fundi could be photographed.

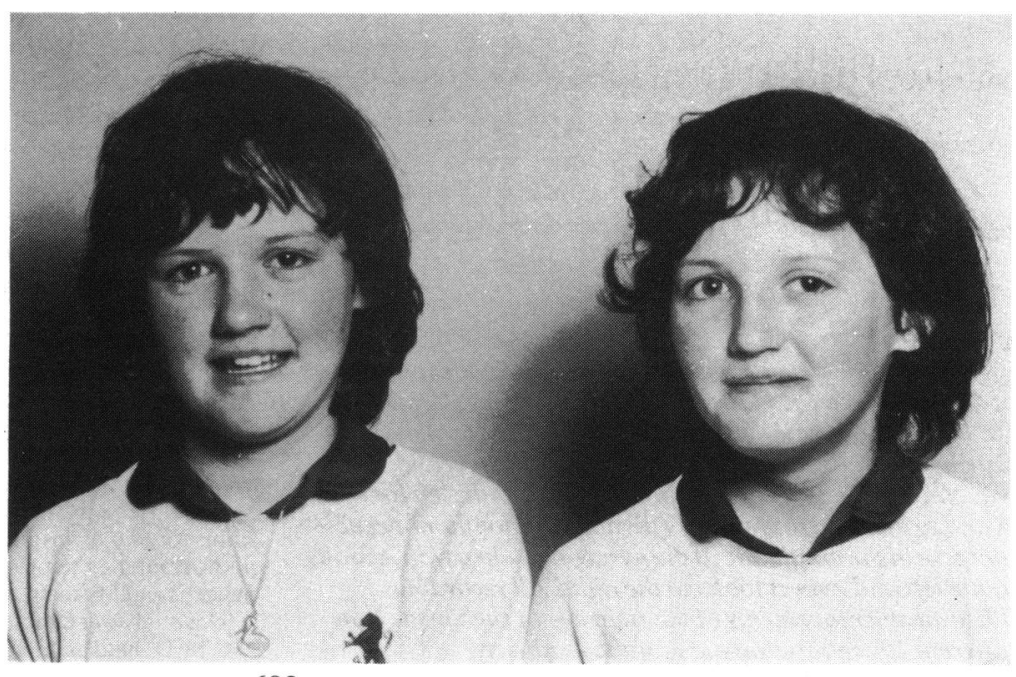

693 
acid phosphatase, PGM, 6PGD, and adenosine deaminiase.

The ocular media and fundi appeared normal. Neither twin had a head turn nor any abnormal head oscillation. Both tanned well in the sun and could be shown to have macular pigment. ${ }^{14}$ Case histories and clinical tests suggested that the nystagmus is idiopathic.

For twin A refraction revealed OD +2.00/ $-4 \cdot 75 \times 406 / 9$, OS $+1 \cdot 50 /-6 \cdot 00 \times 1606 / 12$; and twin B, OD $+1.50 /-4.50 \times 25,6 / 18$, OS $+1 \cdot 75 /$ $-5 \cdot 00 \times 155,6 / 18-2$. Visual acuities were taken when both the head and the eyes were in the primary position. Photoelectric keratoscope ${ }^{15}$ measurements confirmed that the astigmatic nature of the refractive errors reflected to a large extent the toroidal shape of the anterior surface of the corneas. The shape factor of each eye, which is a measure of the rate of peripheral flattening of the cornea, was computed and found not to differ significantly from that of the normal population.

Infrared eye movement recordings were made of

$$
\text { 10\% Nwin A }
$$

Fig. 2 Infrared eye movement recordings of the nystagmus of the twins taken at 5 different positions of gaze: Centre (C), $10^{\circ}$ and $20^{\circ}$ to the right $(\mathrm{R})$ and $10^{\circ}$ and $20^{\circ}$ to the left $(\mathrm{L})$. During central gaze both twins have a pseudocycloid waveform. The fast phase is directed towards the left for twin $A$ and to the right for twin $B$. This accounts for the noticeable increase in the amplitude of the nystagmus when twin A looks to the left and twin B looks to the right. All recordings illustrate the movements of the right eye of each twin. Note different $10^{\circ}$ calibration bars for the 2 subjects. the nystagmus with both eyes being monitored simultaneously. For both twins the nystagmus was bilateral, and the movement was almost exclusively in the horizontal plane. Fig. 2 illustrates the nystagmus waveforms in 5 positions of gaze; the primary position (C), $\pm 10^{\circ}$ and $\pm 20^{\circ}$ from centre. During central fixation both twins have a pseudocycloid waveform, but the fast phases are in opposite directions, with the fast phase to the left for twin A to the right for twin B. As Dell'Osso and Daroff ${ }^{8}$ have pointed out, this waveform is often misidentified as being pendular if position only is monitored. With the aid of a velocity record the waveform can be seen to consist of an accelerating drift off target which is terminated by a braking saccade and followed by a decelerating slow eye movement which brings the eyes back on target. In accordance with Dell'Osso and Daroff ${ }^{8}$ we defined the direction of the pseudocycloid nystagmus as the direction of the braking saccade independent of its amplitude.

The flattened peaks seen in the waveform of twin A would suggest a foveation time greater in duration than that of her sister. This is probably the explanation for the differences found in their visual acuity, the higher visual acuity of twin A being associated with the retinal image spending longer periods of time within the foveal area. Null zones were found in opposite directions of gaze, being on gaze right for twin A and gaze left for twin B. This was not entirely unexpected, particularly in view of the direction of the fast beats monitored on central fixation. In neither twin did the act of convergence attenuate the nystagmus.

\section{Discussion}

Though Forssman and Ringner ${ }^{16}$ have estimated the frequency of idiopathic $\mathrm{CN}$ in the general population to be 1 in 1,000 males and 1 in 2,800 females, the chances of encountering monozygotic twin girls with idiopathic $\mathrm{CN}$ are, to say the least, small. It is therefore regrettable that the only other description of such a case to be found in the literature should omit any quantitative reference to the nystagmus waveform. ${ }^{17}$ In this study we have established that the characteristics of the nystagmus waveforms for our monozygotic twins are indeed dissimilar. This being the case, and in view of the common mode of inheritance, it seems reasonable to suppose that these differences result from environmental influences.

We are greatly indebted to Dr Michael Connor, of the West of Scotland Regional Genetics Centre, for confirming the monozygotic status of the twins; Ian Smith, of Glasgow Eye Infirmary, for photographing the twins; Ms W. Wiggie for translating the German paper ${ }^{17}$; and Ms Janice Patrick for typing the manuscript.

This study was supported by an MRC Project Grant G979/1025N C.M.D. held an MRC studentship (77/7291). 


\section{References}

1 Abadi RV. The effects of early anomalous visual inputs on orientation selectivity. Perception 1974; 3: 141-50.

2 Abadi RV, Sandikcioglu M. Visual resolution in congenital pendular nystagmus. Am J Optom Physiol Opt 1975; 52: 573-81.

3 Abadi RV, King-Smith PE. Congenital nystagmus modifies orientation detection. Vision Res 1979; 19: 1409-11.

4 Dell'Osso LF, Gauthier G, Lieberman G, Stark L. Eye movement recordings as a diagnostic tool in a case of congenital nystagmus. Am J Optom Physiol Opt 1972; 49: 3-13.

5 Dell'Osso LF. Fixation characteristics in hereditary congenital nystagmus. Am J Optom Physiol Opt 1973; 50: 85-90.

6 Abadi RV, Sandikcioglu M. Electro-oculographic responses in a case of bilateral idiopathic nystagmus. Br J Physiol Opt 1974; 29: 73-85.

7 Dell'Osso LF, Flynn JT, Daroff RB. Hereditary congenital nystagmus. Arch Ophthalmol 1974; 92: 366-74.

8 Dell'Osso LF, Daroff RB. Congenital nystagmus waveforms and foveation strategy. Doc Ophthalmol 1975; 39: 155-82.

9 Yee RD, Wong EK, Baloh MD, Honrubia V. A study of congenital nystagmus: waveforms. Neurology (Minneap) 1976; 26: 326-33.
10 Gresty, MA, Halmagyi GM. Head shaking in congenital nystagmus. In: Cohen B, ed. Vestibular and oculomotor physiology. Ann NY Acad Sci 1982; 374: 614-8.

11 Ciuffreda KJ. Jerk nystagmus: some new findings. Am J Optom Physiol Opt 1979; 56: 521-30.

12 Schmidt D. Congenital nystagmus: Clinical Aspects. In: Lennerstrand G, Zee DS, Keller EL, eds. Functional basis of ocular motility disorders. Wenner-Gren Symposium Series. Oxford: Pergamon Press, 1982: 37: 123-7.

13 Dell'Osso LF. Congenital nystagmus: Basic aspects. In: Lennerstrand G, Zee DS, Keller EL, eds. Functional basis of ocular motility disorders. Wenner-Gren Symposium Series. Oxford: Pergamon Press, 1982: 37: 129-38.

14 Abadi RV, Dickinson CM. Monochromatic fundus photography of the human albino. Arch Ophthalmol in press.

15 Bibby MM. Computer-assisted photokeratoscopy and contact lens design. Optician 1976; 171: 4423, 37-44; 4424, 11-17.

16 Forssman B, Ringner B. Prevalence and inheritance of congenital nystagmus in a Swedish population. Ann Hum Genet 1971; 35: $139-47$.

17 Vogel Von F, Balthaser G. Über ein männliches eineiiges Zwillingspaar mit angerborenem Nystagmus und Myopie. Klin Mionatsbl Augenheilkd 1956; 128: 456-9. 